\title{
Intercostal artery management in thoracoabdominal aortic surgery: To reattach or not to reattach?
}

\author{
Rana O. Afifi, MD, ${ }^{\text {a,b }}$ Harleen K. Sandhu, MD, MPH, ${ }^{a}$ Syed T. Zaidi, BS, ${ }^{a}$ Ernest Trinh, MS, ${ }^{a}$ \\ Akiko Tanaka, MD, PhD, ${ }^{a}$ Charles C. Miller III, PhD, ${ }^{a}$ Hazim J. Safi, MD, FACS,,${ }^{\mathrm{a} b}$ and \\ Anthony L. Estrera, MD, FACS ${ }^{\mathrm{a}, \mathrm{b}}$
}

\begin{abstract}
Background: The need for intercostal artery (ICA) reattachment in surgery for descending thoracic aortic aneurysm (DTAA) or thoracoabdominal aortic aneurysm (TAAA) remains controversial. We reviewed our experience over a 14year period to assess the effects of ICA management on neurologic outcome after DTAA/TAAA repair.

Methods: Intraoperative data were reviewed to ascertain the status of T3-12 ICAs and L1-4 ICAs. Arteries were classified as reattached, ligated, occluded, or not exposed. Temporality of reattachment or ligation in response to an intraoperative ischemic event (ie, loss of motor evoked potentials [MEPs]) was noted. Adjustment for other predictors of immediate or delayed paraplegia (DP) was performed by multiple logistic regression. The effects of specific artery level and type of reattachment technique were assessed using stratified contingency tables.
\end{abstract}

Results: A total of 1096 DTAA/TAAAs were performed between 2001 and 2014. The mean patient age was $64 \pm 15$ years, and $37 \%$ were female. Spinal cord ischemia was identified in $10 \%$ of patients, including $35(3 \%)$ immediate cases and $77(7 \%)$ DP cases. Overall DP resolution was $47 \%$ at discharge. ICA ligation and intraoperative MEP changes were strong predictors of postoperative paraplegia. Multivariable analysis demonstrated that T8-12 ICA ligation significantly increased the risk for paraplegia (odds ratio, 1.3/artery; $P<.041$ ) even after adjustment for age $>65$ years, glomerular filtration rate, extent of II/III aneurysm, increased operative time, and intraoperative MEP loss.

Conclusions: Loss of intraoperative MEPs is serious, and increases the risk of paraplegia in any ICA management strategy. Even with intact MEP, ligation of T8-12 ICAs is associated with increased risk. These findings support reattachment of T8-12 ICAs whenever feasible. (J Thorac Cardiovasc Surg 2018;155:1372-8)

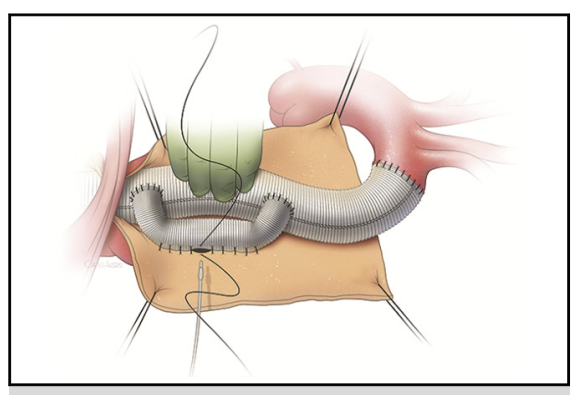

Loop graft for ICA reattachment. C) 2018 Department of Cardiothoracic and Vascular Surgery, McGovern Medical School.

\section{Central Message}

Loss of motor evoked potentials (MEPs), regardless of intercostal artery (ICA) management and ligation of T8-12 ICA — even with intact MEPs-increases the risk of paraplegia. This supports reattachment of T812 ICA whenever feasible, to prevent paraplegia.

\section{Perspective}

Paraplegia following thoracoabdominal aortic aneurysm repair remains a devastating complication. Despite the use of spinal cord protective adjuncts, paraplegia rates are not negligible. Whether or not to reattach the intercostal artery (ICA) remains controversial. Our results show that ligation of T812 ICA increases the risk of paraplegia. This risk is further compounded when motor evoked potential changes occur. T8-12 ICA should be reattached expeditiously to reduce these risks.

See Editorial Commentary page 1379.

See Editorial page 1357.

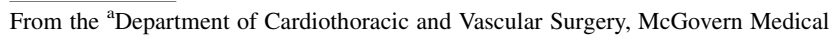
School at The University of Texas Health Science Center at Houston (UTHealth), Houston, Tex; and ${ }^{\mathrm{b}}$ Memorial Hermann Heart \& Vascular Institute, Houston, Tex. Drs Afifi and Sandhu contributed equally to this article.

Read at the 97th Annual Meeting of The American Association for Thoracic Surgery, Boston, Massachusetts, April 29-May 3, 2017.

Received for publication May 17, 2017; revisions received Nov 10, 2017; accepted for publication Nov 17, 2017; available ahead of print Feb 2, 2018.

Address for reprints: Rana O. Afifi, MD, Department of Cardiothoracic and Vascular Surgery, McGovern Medical School at UTHealth, 6400 Fannin St, Ste 2850, Houston, TX 77030 (E-mail: Rana.o.afifi@uth.tmc.edu).

$0022-5223 / \$ 36.00$

Copyright (c) 2018 by The American Association for Thoracic Surgery

https://doi.org/10.1016/j.jtcvs.2017.11.072
Spinal cord ischemia with paraplegia remains a dreadful complication following descending thoracic aortic aneurysm (DTAA) or thoracoabdominal aortic aneurysm (TAAA) repair, with devastating outcomes, including higher early mortality and a lower long-term survival. ${ }^{1-4}$

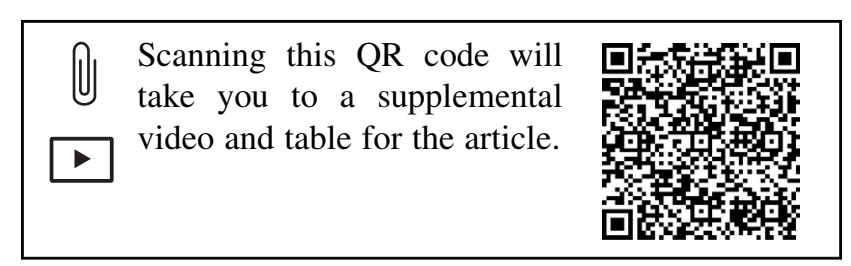



Abbreviations and Acronyms
DTAA $=$ descending thoracic aortic aneurysm
$\mathrm{DP}=$ delayed paraplegia
$\mathrm{EP} \quad=$ early paraplegia
ICA $=$ intercostal artery
MEP $=$ motor evoked potential
$\mathrm{OR}=$ odds ratio
TAAA $=$ thoracoabdominal aortic aneurysm

In 1998, Safi et $\mathrm{al}^{2}$ concluded that intercostal artery (ICA) reattachment is of the utmost importance for preventing paraplegia following TAAA repair. The group reported that reattachment of T11 and 12 ICAs significantly reduced the risk of overall paraplegia, and reattachment of T9 and 10 ICAs significantly decreased the risk for delayed paraplegia (DP).

Over the past 2 decades, many-including our grouphave studied spinal cord protection and spinal cord injury monitoring during open and endovascular TAAA repair. ${ }^{5-}$

${ }^{19}$ Our technique for TAAA repair and ICA management has evolved over the years. It includes the routine use of adjuncts for spinal cord protection, intraoperative neurophysiologic monitoring, and selective ICA reattachment, as well as changes in the surgical technique of ICA reattachment (island patch, loop graft, and end graft).

In the present study, we reviewed our experience over a 14-year period and assessed the effects of ICA management on neurologic outcome after DTAA/TAAA repair.

\section{METHODS}

The Committee for the Protection of Human Subjects at the McGovern Medical School at UTHealth, the local Institutional Review Board, approved this study. The requirement of informed consent was waived. This was an observational study, using data collected from a single department. We reviewed all cases of open DTAA/TAAA repair performed between 2001 and 2014. We retrospectively reviewed patient characteristics, intraoperative variables, and complications, including intraoperative data, to ascertain the status of T3-12 ICAs and L1-4 ICAs. We also evaluated postoperative paraplegia in this cohort.

\section{Definitions}

Postoperative early paraplegia (EP) was defined as paraplegia or paraparesis observed once the patient awakened from anesthesia, regardless of severity. Delayed paraplegia (DP) was defined as new paraplegia or paraparesis occurring postoperatively in a previously neurologically intact patient. The degree of paraplegia was characterized using the modified Tarlov score; a score of 0,1 , or 2 was deemed paraplegia, and a score of 3 or 4 denoted paraparesis.

\section{ICA Status Determination}

For each artery level, starting with the common takeoff of thoracic arteries 3 and 4 and extending to the lumbar artery 4 , we determined whether the artery was (1) natively occluded (ie, atrophied or otherwise not bleeding) and, thus, not in need of management; (2) ligated; (3) reattached into the aortic circulation; or (4) not exposed in the surgical field and thus not in need of management. For the arteries that were reattached, we noted the method of reattachment: anastomosed as an island directly into the graft, anastomosed singly end-to-end with individual bypass grafts, or attached end-to-side with a loop graft (Figure 1). We also noted the temporality of the reattachment with respect to MEP loss (provoked) and to MEP recovery if signals recovered.

\section{MEP Measures of Neurologic Function}

Intraoperative MEP recordings were used routinely after 2004. Signals were considered lost when bilateral lower leg signals had reduced latency and amplitude, and were considered to reflect spinal ischemia by the attending neurophysiologist. Whether, when, and by what maneuver (eg, anesthesia maneuvers, increase in distal aortic perfusion, resumption of distal pulsatile flow, ICA implantation) signals were regained was noted, and the temporal proximity of ICA reattachment to signal loss and return was noted, as described above.

\section{STATISTICAL METHODS}

Categorical univariate demographic data were analyzed by contingency table methods, and continuous data were analyzed using the unpaired $t$ test with meaningful transformations as appropriate or nonparametric methods.

The analysis of ICA management strategy focused mainly on thoracic ICA levels 8 to 12 . This was due in part to the fact that T3-7 and L1-4 were not manipulated in the majority of repairs, and the largest proportion of variance in outcome (paraplegia) explained by management strategy arose from the T8-12 region. This area has been characterized as the critical region for maintenance of the spinal cord circulation. ${ }^{2,20}$

Indicator variables were coded to identify the ICA management strategy at each level. Because of the heterogeneity of management across artery levels, a score for each type of management was constructed to summarize the impact over multiple arterial beds, and permitted us to develop a common scale (unit risk/artery regardless of exact location) that could be used to measure the impact of various management strategies across aneurysm sizes and could be included in multivariable statistical models to extract data on independent effects of management strategies from the complex interplay of patient characteristics and extent of aortic disease. The scores were the simple linear sum of $1 / 0$ indicator variables for each management strategy. Each patient received a cumulative point score that represented the number of ICAs natively occluded, ligated, or reattached.

Indicator variables for temporality of MEP loss-specifically the determination of whether ICA reattachment was provoked by loss of signals - were coded, as were variables indicating the nature and temporal sequence of intraoperative countermeasures leading to signal restoration. These MEP parameters were combined with ICA management strategies in both stratified contingency table and regression-based multivariable analyses to assess the impact of ICA management in the context of contemporaneous intraoperative spinal perfusion measures.

Intraoperative measures, including operative time, blood product use, and complications, were analyzed using 


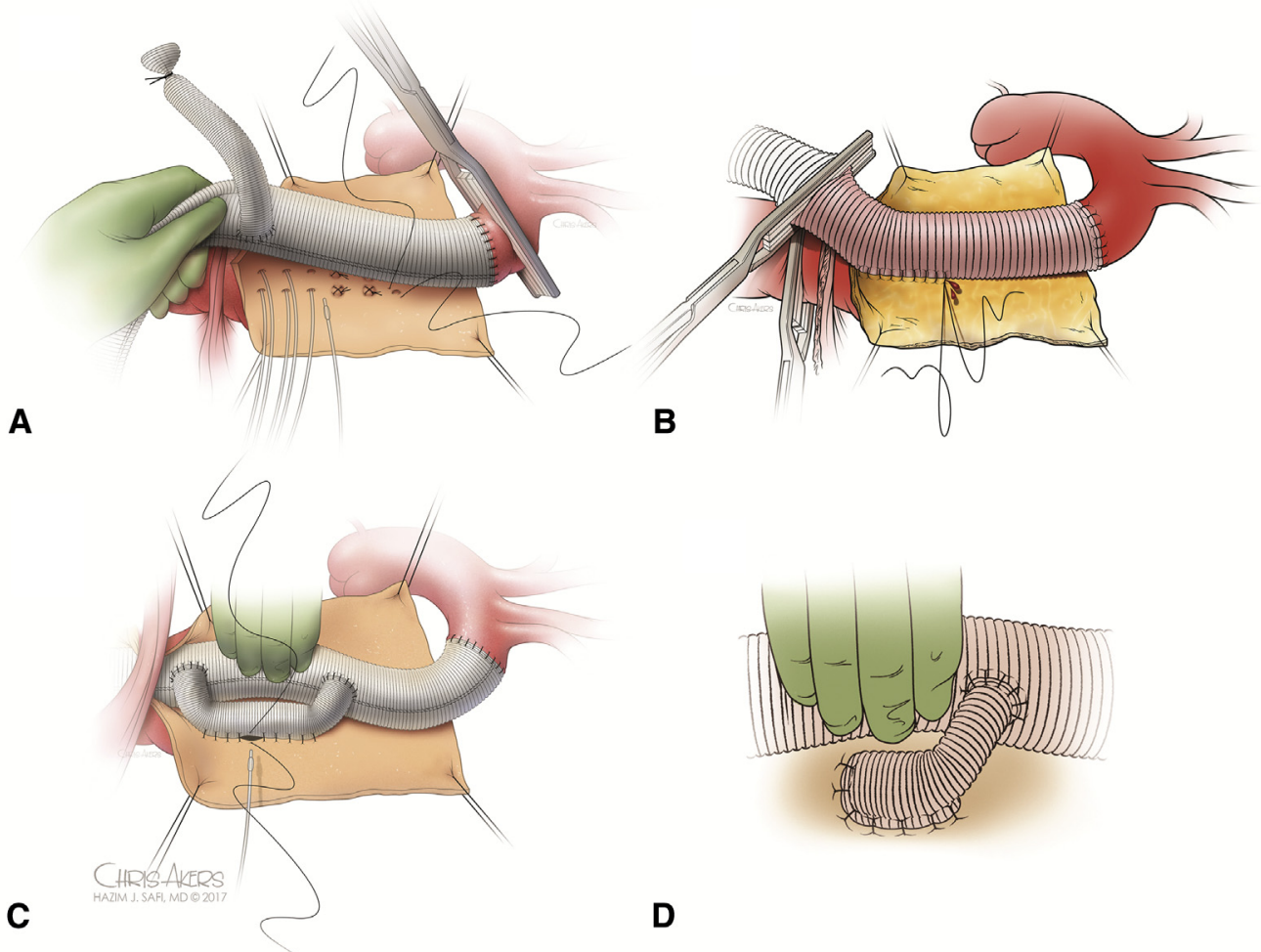

FIGURE 1. Illustration of intercostal artery (ICA) surgical management in thoracoabdominal aortic repair. A, ICA ligation. B, Inclusion technique (island patch) for ICA reattachment. C, Loop graft for ICA reattachment. D, End graft for ICA reattachment. (C) 2018 Department of Cardiothoracic and Vascular Surgery, McGovern Medical School.

multivariable regression models, with management strategy scores modeled simultaneously as independent predictor variables. Furthermore, variations in the magnitude of associations across aneurysm sizes were assessed by stratified regression models to determine whether various ICA management strategies had differential effects in aneurysms of different extents. These measures, reported in Table E1, are multiple regression coefficients shown as increase per unit per artery treated and their associated $P$ values. For times, units represent minutes added to or subtracted from the population mean per artery treated for that aneurysm extent. For blood products, they are unit volumes added or subtracted. For complications, the values are reported as odds ratio (OR).

Neurologic outcome (paraplegia/paraparesis) was assessed using univariate and stratified contingency table methods and multiple regression approaches, accounting for ICA management score and MEP-related temporality measures. Final adjusted models were developed using multiple logistic regression analysis. All computations were performed using SAS version 9.4 (SAS Institute, Cary, NC).

\section{RESULTS}

Between May 2001 and June 2014, we performed 1096 D/TAAAs at our hospital. Patient demographic data are presented in Table 1.

\section{Intraoperative Findings}

The impacts of various ICA management strategies on intraoperative time, blood product use, and complications are summarized by aneurysm extent in Table E1. In general, ICA attachment by an island patch technique increased operative times by 1.0 to 1.2 minutes per artery. Therefore, implanting 5 ICAs increases the total operative by 5 to $6 \mathrm{mi}-$ nutes. Ligation tended to reduce relative time by roughly the same magnitude. Although some of these results were statistically significant, the main finding is the little time saved by ligation versus reattachment-approximately 5 to $10 \mathrm{mi}-$ nutes in a typical case. Bypass conduits were also associated with increased operative times and were more commonly used when coagulopathy and increased transfusion were present. These associations were most prominent in more extensive aneurysms (TAAA I, II, and III).

\section{Analysis of Key ICA: T8-12}

As explained above, our focused analysis of ICA management presented below reflects thoracic intercostal levels 8-12.

EP was present in 35 of 1096 patients (3.2\%), and DP occurred in 77 of the 1061 patients without EP (7.3\%), for an overall rate of $10 \%$ (110 of 1096) for any paraplegia. The crude rate of EP was $1.9 \%$ in patients with no ICA manipulation, $3.4 \%$ in those with all manipulated arteries ligated, and $4.5 \%$ in those with some combination of ligation 
TABLE 1. Preoperative patient demographic data

\begin{tabular}{|c|c|c|c|c|c|}
\hline Variable & $\begin{array}{c}\text { Overall } \\
(n=1096)\end{array}$ & $\begin{array}{l}\text { ICA not manipulated } \\
\quad(\mathbf{n}=\mathbf{3 1 5})\end{array}$ & $\begin{array}{l}\text { ICA ligated } \\
\text { only }(n=273)\end{array}$ & $\begin{array}{l}\text { ICA reattached } \\
\quad(\mathbf{n}=\mathbf{5 0 8})\end{array}$ & $P$ value \\
\hline Age, yr, median (interquartile range) & $67(56-74)$ & $70(63-76)$ & $62(50-72)$ & $66(56-74)$ & $<.001$ \\
\hline Female sex, n $(\%)$ & $409(37.3)$ & $118(37.5)$ & $110(40.3)$ & $181(35.6)$ & .437 \\
\hline Hypertension, $\mathrm{n}(\%)$ & $973(88.8)$ & $281(89.2)$ & $234(85.7)$ & $458(90.1)$ & .165 \\
\hline Diabetes, $\mathrm{n}(\%)$ & $132(12.0)$ & $40(12.7)$ & $33(12.1)$ & $59(11.6)$ & .897 \\
\hline Coronary artery disease, $\mathrm{n}(\%)$ & $313(28.6)$ & $118(37.5)$ & 46 (16.9) & $149(29.3)$ & $<.001$ \\
\hline Chronic obstructive pulmonary disease, $\mathrm{n}(\%)$ & $450(41.1)$ & $157(49.8)$ & $90(32.9)$ & $203(39.9)$ & $<.001$ \\
\hline Any smoking history, $\mathrm{n}(\%)$ & $769(70.2)$ & $253(80.3)$ & $168(61.5)$ & $348(68.5)$ & $<.001$ \\
\hline Peripheral vascular disease, $\mathrm{n}(\%)$ & $223(20.4)$ & $94(29.8)$ & $40(14.7)$ & $89(17.5)$ & $<.001$ \\
\hline Previous stroke, $\mathrm{n}(\%)$ & $98(8.9)$ & $32(10.2)$ & $21(7.7)$ & $45(8.9)$ & .577 \\
\hline Rupture, n (\%) & $136(12.4)$ & $53(16.8)$ & $42(15.4)$ & $41(8.1)$ & $<.001$ \\
\hline \multicolumn{6}{|l|}{ Chronic kidney disease stage, $\mathrm{n}(\%)$} \\
\hline 1: $\mathrm{eGFR} \geq 90$ & $376(35.2)$ & $72(23.6)$ & $123(46.1)$ & $181(36.6)$ & $<.001$ \\
\hline 2: eGFR 60-89 & $280(26.2)$ & $62(20.3)$ & $76(28.5)$ & $142(28.7)$ & .018 \\
\hline 3a: eGFR 44-59 & $191(17.9)$ & $70(22.9)$ & $26(9.7)$ & $95(19.2)$ & $<.001$ \\
\hline 3b: eGFR 30-43 & 127 (11.9) & $51(16.7)$ & $23(8.6)$ & $53(10.7)$ & .007 \\
\hline 4: eGFR 15-29 & $71(6.7)$ & $39(12.8)$ & $15(5.6)$ & $17(3.4)$ & $<.001$ \\
\hline 5: eGFR $<15$ & $22(2.1)$ & $11(3.6)$ & $4(1.5)$ & $7(1.4)$ & .084 \\
\hline Connective tissue disorder, $\mathrm{n}(\%)$ & 205 (18.7) & 43 (13.7) & $62(22.7)$ & $100(19.7)$ & .014 \\
\hline Marfan syndrome, $\mathrm{n}(\%)$ & $82(7.5)$ & $14(4.4)$ & $19(6.9)$ & $49(9.7)$ & .021 \\
\hline Chronic dissection, $\mathrm{n}(\%)$ & $379(34.6)$ & $40(12.7)$ & $111(40.7)$ & $228(44.9)$ & $<.001$ \\
\hline Previous proximal aortic repair, n $(\%)$ & $253(23.1)$ & $35(11.1)$ & $66(24.2)$ & $152(29.9)$ & $<.001$ \\
\hline Previous distal aortic repair, n (\%) & $296(27.0)$ & $123(39.1)$ & $38(13.9)$ & $135(26.6)$ & $<.001$ \\
\hline Previous aortic valve replacement, $\mathrm{n}(\%)$ & $135(12.3)$ & $18(5.7)$ & $39(14.3)$ & $78(15.4)$ & $<.001$ \\
\hline Emergency, n (\%) & $116(10.6)$ & 49 (15.6) & $35(12.8)$ & $32(6.3)$ & $<.001$ \\
\hline Redo, n (\%) & $196(17.9)$ & $89(28.3)$ & $29(10.6)$ & $78(15.4)$ & $<.001$ \\
\hline \multicolumn{6}{|l|}{ Extent of aneurysm, $n(\%)$} \\
\hline TAAA I & 127 (11.6) & $16(5.1)$ & $23(8.4)$ & $88(17.3)$ & $<.001$ \\
\hline TAAA II & $113(10.3)$ & $10(3.2)$ & $11(4.0)$ & $92(18.1)$ & $<.001$ \\
\hline TAAA III & $118(10.8)$ & $24(7.6)$ & $15(5.5)$ & $79(15.6)$ & $<.001$ \\
\hline TAAA IV & $217(19.8)$ & $186(59.2)$ & $8(2.9)$ & $23(4.5)$ & $<.001$ \\
\hline TAAA V & $75(6.9)$ & $13(4.1)$ & $15(5.5)$ & $47(9.3)$ & .011 \\
\hline DTAA & 445 (40.6) & 65 (20.7) & $201(73.6)$ & $179(35.2)$ & $<.001$ \\
\hline
\end{tabular}

ICA, Intercostal artery; $e G F R$, estimated glomerular filtration rate $\left(\mathrm{mL} / \mathrm{min} 1.73 \mathrm{~m}^{2}\right) ; T A A A$, thoracoabdominal aortic aneurysm; DTAA, descending thoracic aortic aneurysm. (C) 2018 Department of Cardiothoracic and Vascular Surgery, McGovern Medical School.

and reattachment $(P=.09)$. For DP, the managementspecific crude rates were $4.2 \%$ in patients with no ICA manipulation, $10.1 \%$ in those with all manipulated arteries ligated, and $9.3 \%$ in those with some combination of ligation and reattachment $(P=.003)$. For the combined paraplegia types, $5.9 \%$ of patients with no ICA manipulation, $13.5 \%$ of those with ligation only, and $13.6 \%$ of those with some combination of ligation and reattachment had paraplegia $(P<.001)$. These results illustrate the complexity of evaluating these data when ICAs may be reattached at some levels and ligated at others, and the score-based cumulative burden of ligation or bypass must be subjected to multivariable modeling to separate these complex effects.
In multivariable logistic regression analysis of ligation and reattachment scores, ligation of ICA was associated with a 1.3-fold increase in odds of any neurologic deficit (EP or DP) per artery ligated in the T8-12 region. This effect persists after adjustment for known risk factors for paraplegia, ${ }^{3}$ age, operative time, and aneurysm extent $(P=.013$; Table 2$)$.

\section{MEP Analysis $(n=660)$}

MEP monitoring began after 2004; therefore, data on MEPs were available for only 660 of our 1096 patients $(60 \%)$. MEP data were lost during surgery in 370 of these 660 patients $(56 \%)$, although 332 of these $(90 \%)$ recovered in the operating room. Of those who recovered, $13(3.5 \%)$ 
TABLE 2. Independent effects of risk factors for postoperative paraplegia

\begin{tabular}{lccc}
\hline \multicolumn{1}{c}{ Variable } & $\begin{array}{c}\text { OR } \\
(\mathbf{9 5} \% \mathbf{~ C I})\end{array}$ & $\begin{array}{c}\text { Attributable } \\
\text { risk, \% } \dagger\end{array}$ & $\boldsymbol{P}$ value $\dagger$ \\
\hline T8-12 ligation (artery ligated) & $1.3(1.1-1.6)$ & $2 \pm 1$ & .041 \\
Age & $1.0(1.0-1.1)$ & $0.3 \pm 0.1$ & $<.001$ \\
TAAA extent II or III & $3.6(2.3-5.7)$ & $13.9 \pm 2.5$ & $<.001$ \\
Pump time, min & $1.01(1.00-1.02)$ & $0.1 \pm 0.03$ & .029 \\
MEP loss & $1.8(1.2-1.8)$ & $5.5 \pm 2$ & .006 \\
\hline
\end{tabular}

$O R$, Odds ratio; $C I$, confidence interval; TAAA, thoracoabdominal aortic aneurysm, $M E P$, motor evoked potential. *Calculations derived from multiple logistic regression analysis for risk modeling for postoperative paraplegia. $\dagger$ Calculations derived from generalized linear model analysis for risk modeling for postoperative paraplegia. Attributable risk interpreted as \% of overall risk of paraplegia is attributable to the corresponding variable. (c) 2018 Department of Cardiothoracic and Vascular Surgery, McGovern Medical School.

did so after anesthesia maneuvers (ie, increasing mean arterial pressure, decreasing intracranial pressure by draining cerebrospinal fluid, and increasing distal aortic perfusion), $74(20 \%)$ did so after distal aortic perfusion, $112(31 \%)$ did so after restoration of distal pulsatile flow, and 133 $(36 \%)$ did so after segmental artery reattachment $(P<.0001$, Cochran-Armitage test for trend). Regardless of ICA management strategy, MEP loss was associated with increased risk of all types of paraplegia (EP, $4.9 \%$ vs $1.0 \%, P=.005$; DP, 10.3 vs $5.5, P=.027 ; 14.6$ vs 6.5 , $P=.001)$. After adjusting for age, aneurysm extent II or III, number of arteries ligated, and operative time, MEP loss had an OR of $1.8(P=.006)$ for any type of paraplegia. Adjusted effects on EP and DP separately were not significant, although the ORs were within the $95 \%$ CI for overall paraplegia. This likely reflects the reduced power of the test, given the smaller event rates for the paraplegia rates separated by time of occurrence and the reduction of the overall sample size by $40 \%$, given the adoption of MEP monitoring only approximately halfway through the cohort time.

\section{DISCUSSION}

Spinal cord ischemia remains a devastating complication of TAAA repair. In 1993, Svensson et $\mathrm{al}^{1}$ reported a paraplegia rate of $31.5 \%$ following an extent II TAAA repair. Since then, with the implementation of adjuncts for spinal cord protection and neurophysiologic monitoring, paraplegia rates have dropped significantly, regardless of the modality of repair, with rates ranging from $3.1 \%$ to as high as $20 \%$ in extent II TAAA., ${ }^{3,17,21,22}$ Despite the success of strategies for shortening the duration of spinal cord injury, increasing spinal cord tolerance, and augmentation of spinal cord perfusion, paraplegia following TAAA repair is far from eliminated.

We recently reported our experience managing TAAA over a 24-year period. ${ }^{3}$ Compared with the "clamp-andgo" era, the rate of EP has decreased dramatically with current management and implementation of adjuncts for spinal cord protection; however, the rate of DP has increased. ${ }^{3}$

Our ICA management strategy has evolved over the years. We moved from obligatory reattachment of T8-12 ICAs to selective reattachment of ICAs based on intraoperative neurophysiologic monitoring (ie, MEPs). ${ }^{3,6}$ Our surgical technique for ICA reattachment has changed in recent years from an inclusion technique with an island patch to reattachment with a loop graft or an end graft, due to the development of patch aneurysms and the need for redo surgery, as we have reported recently. ${ }^{23}$ As shown in Table E1, this change in surgical technique has had little effect on operative time and intraoperative complication rates. We have also developed an intraoperative protocol with a series of maneuvers implemented in the event of loss of MEPs. ${ }^{6}$ We first used anesthesia measures for improving spinal cord perfusion, including increasing mean arterial pressure, decreasing intracranial pressure by draining cerebrospinal fluid, and increasing distal aortic perfusion. This was followed by restoring pulsatile flow to the pelvic circulation as quickly as possible. In cases in which MEPs did not return, we proceeded with reattachment of patent T8-12 ICAs with a graft (loop or end graft). As described in Results, 90\% of lost MEPs were regained by the end of surgery by implementing this protocol. The importance of such maneuvers has been described in endovascular repair of TAAA with similar rates of regained

TABLE 3. Effect of intraoperative MEP loss and T8-12 ICA management on postoperative neurologic deficit

\begin{tabular}{|c|c|c|c|c|}
\hline Variable & ICA not manipulated, n (\%) & ICA ligated, n (\%) & ICA reattached, $n(\%)$ & $P$ value \\
\hline $\begin{array}{l}\text { Intraoperative MEP loss } \\
\quad(\mathrm{n}=370)\end{array}$ & $\mathrm{n}=133$ & $\mathrm{n}=57$ & $\mathrm{n}=180$ & \\
\hline Early paraplegia & $4(3.0)$ & $2(3.5)$ & $12(6.7)$ & .289 \\
\hline Delayed paraplegia & $11(8.3)$ & $5(8.8)$ & $22(12.2)$ & .482 \\
\hline Overall paraplegia & $14(10.5)$ & $7(12.3)$ & $33(18.3)$ & .133 \\
\hline $\begin{array}{l}\text { No intraoperative MEP loss } \\
\quad(\mathrm{n}=290)\end{array}$ & $\mathrm{n}=156$ & $\mathrm{n}=37$ & $\mathrm{n}=96$ & \\
\hline Early paraplegia & $1(0.6)$ & $1(2.6)$ & $1(1.0)$ & .554 \\
\hline Delayed paraplegia & $6(3.9)$ & $5(13.2)$ & $5(5.2)$ & .078 \\
\hline Overall paraplegia & $7(4.5)$ & $6(15.8)$ & $6(6.3)$ & .041 \\
\hline
\end{tabular}

ICA, Intercostal artery; MEP, motor evoked potential. @ 2018 Department of Cardiothoracic and Vascular Surgery, McGovern Medical School. 


\section{Paraplegia and TAAA repair}

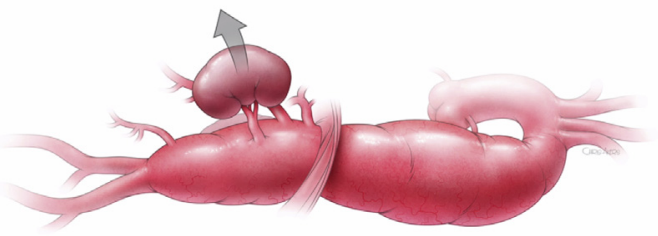

VIDEO 1. Intercostal artery management in thoracoabdominal aortic surgery: to reattach or not to reattach? (C) 2018 Department of Cardiothoracic and Vascular Surgery, McGovern Medical School. Video available at: http://www.jtcvsonline.org/article/S0022-5223(17)32766-6/fulltext.

MEPs; however, endovascular repair precludes the possibility of reattaching ICAs. ${ }^{14}$

Despite the use of spinal cord protection adjuncts and intraoperative protocols for regaining MEPs, the paraplegia rate in this cohort is not negligible. In this cohort, EP occurred in $3.1 \%$ of the patients, and $7.3 \%$ had DP. We previously reported that $45.2 \%$ of patients with DP recovered before discharge. ${ }^{3}$ The 2 most significant findings in this study are summarized in Tables 2 and 3, where we identify 5 independent risk factors for paraplegia, 3 of which-age, pump time, and extent of aneurysm - we reported previously. ${ }^{3}$ ICA ligation is associated with a 1.3-fold increase in the odds of any paraplegia (EP or DP) per artery ligated in the T8-12 region, and this increased risk was statistically significant even with intact intraoperative MEPs as shown in Table 3. Loss of MEPs was also associated with 1.8-fold increase in odds of any neurologic deficit, regardless of ICA management and despite recovery of $90 \%$ at the end surgery.

Today, more than ever-especially in the endovascular era-the question to "reattach or not to reattach ICAs?" divides the surgical community.

Our results emphasize the importance of reattaching patent ICAs in the T8-12 region, regardless of intraoperative neurophysiologic monitoring, and challenges us to continue developing and investigating better ways for maintaining spinal cord perfusion-especially when using endovascular techniques, for which ICA reattachment is not feasible (see Video 1).

\section{Study Limitations}

As a retrospective study, this study must be viewed with certain limitations and biases. Another limitation is related to the fact that MEP monitoring began only after 2004 and, thus, data on MEPs were available for only $60 \%$ of the cohort.

The analysis focused mainly on T8-12 ICAs, mainly because ICAs in regions T3-7 and L1-4 were not manipulated in the majority of repairs. In addition, in this study, we lacked anatomic information regarding collateral circulation status (subclavian artery, hypogastric arteries) and its affect on paraplegia in this cohort.

\section{CONCLUSIONS}

Loss of intraoperative MEPs, regardless of ICA management and ligation of T8-12 ICAs-even with intact MEPs-is associated with increased risk of DP. These findings support reattachment of T8-12 ICAs, whenever feasible, to improve spinal cord perfusion and prevent DP.

\section{Conflict of Interest Statement}

Dr Estrera is a consultant for W.L. Gore and Associates. All other authors have nothing to disclose with regard to commercial support.

\section{References}

1. Svensson LG, Crawford ES, Hess KR, Coselli JS, Safi HJ. Experience with 1509 patients undergoing thoracoabdominal aortic operations. J Vasc Surg. 1993;17: 357-68; discussion 368-70.

2. Safi HJ, Miller CC III, Carr C, Iliopoulos DC, Dorsay DA, Baldwin JC. Importance of intercostal artery reattachment during thoracoabdominal aortic aneurysm repair. J Vasc Surg. 1998;27:58-66; discussion 66-8.

3. Estrera AL, Sandhu HK, Charlton-Ouw KM, Afifi RO, Azizzadeh A, Miller CC III, et al. A quarter century of organ protection in open thoracoabdominal repair. Ann Surg. 2015;262:660-8.

4. Conrad MF, Ye JY, Chung TK, Davison JK, Cambria RP. Spinal cord complications after thoracic aortic surgery: long-term survival and functional status varies with deficit severity. J Vasc Surg. 2008;48:47-53.

5. Safi HJ, Campbell MP, Ferreira ML, Azizzadeh A, Miller CC. Spinal cord protection in descending thoracic and thoracoabdominal aortic aneurysm repair Semin Thorac Cardiovasc Surg. 1998;10:41-4.

6. Estrera AL, Sheinbaum R, Miller CC III, Harrison R, Safi HJ. Neuromonitorguided repair of thoracoabdominal aortic aneurysms. J Thorac Cardiovasc Surg. 2010;140(6 Suppl):S131-5; discussion S142-6.

7. Estrera AL, Miller CC III, Huynh TT, Azizzadeh A, Porat EE, Vinnerkvist A, et al. Preoperative and operative predictors of delayed neurologic defici following repair of thoracoabdominal aortic aneurysm. J Thorac Cardiovasc Surg. 2003;126:1288-94.

8. Estrera AL, Miller CC III, Chen EP, Meada R, Torres RH, Porat EE, et al. Descending thoracic aortic aneurysm repair: 12-year experience using distal aortic perfusion and cerebrospinal fluid drainage. Ann Thorac Surg. 2005;80:1290-6; discussion 1296.

9. Bischoff MS, Brenner RM, Scheumann J, Zoli S, Di Luozzo G, Etz CD, et al. Staged approach for spinal cord protection in hybrid thoracoabdominal aortic aneurysm repair. Ann Cardiothorac Surg. 2012;1:325-8.

10. Griepp RB, Griepp EB. Spinal cord perfusion and protection during descending thoracic and thoracoabdominal aortic surgery: the collateral network concept. Ann Thorac Surg. 2007;83:S865-9; discussion S890-2.

11. Geisbüsch S, Stefanovic A, Koruth JS, Lin HM, Morgello S, Weisz DJ, et al. Endovascular coil embolization of segmental arteries prevents paraplegia after subsequent thoracoabdominal aneurysm repair: an experimental model. J Thorac Cardiovasc Surg. 2014;147:220-6.

12. Luozzo Di G, Wilderman M, Pawale A, McCullough J, Griepp RB. Planned staged repair of thoracoabdominal aortic aneurysms to minimize spinal cord injury: a proof of concept. Aorta (Stamford). 2015;3:177-80.

13. Griepp EB, Griepp RB. The collateral network concept: minimizing paraplegia secondary to thoracoabdominal aortic aneurysm resection. Tex Heart Inst J 2010;37:672-4.

14. Mendes BC, Oderich GS. Endovascular repair of thoracoabdominal aortic aneurysm using the off-the-shelf multibranched t-Branch stent graft. J Vasc Surg. 2016:63:1394-9.e2.

15. Sundt TM, Fleming MD, Oderich GS, Torres NE, Li Z, Lenoch J, et al. Spinal cord protection during open repair of thoracic and thoracoabdominal aortic aneurysms using profound hypothermia and circulatory arrest. J Am Coll Surg. 2011; 212:678-83; discussion 684-5.

16. Coselli JS, LeMaire SA, Köksoy C, Schmittling ZC, Curling PE. Cerebrospinal fluid drainage reduces paraplegia after thoracoabdominal aortic aneurysm repair: results of a randomized clinical trial. J Vasc Surg. 2002;35:631-9. 
17. Etz CD, Weigang E, Hartert M, Lonn L, Mestres CA, Di Bartolomeo R, et al. Contemporary spinal cord protection during thoracic and thoracoabdominal aortic surgery and endovascular aortic repair: a position paper of the vascular domain of the European Association for Cardio-Thoracic Surgery. Eur J Cardiothorac Surg. 2015;47:943-57.

18. Maurel B, Delclaux N, Sobocinski J, Hertault A, Martin-Gonzalez T, Moussa M, et al. The impact of early pelvic and lower limb reperfusion and attentive perioperative management on the incidence of spinal cord ischemia during thoracoabdominal aortic aneurysm endovascular repair. Eur J Vasc Endovasc Surg. 2015;49:248-54.

19. Acher C, Acher CW, Marks E, Wynn M. Intraoperative neuroprotective interventions prevent spinal cord ischemia and injury in thoracic endovascular aortic repair. J Vasc Surg. 2016;63:1458-65.

20. Tanaka H, Ogino H, Minatoya K, Matsui Y, Higami T, Okabayashi H, et al The impact of preoperative identification of the Adamkiewicz artery on descending and thoracoabdominal aortic repair. J Thorac Cardiovasc Surg. 2016;151:122-8
21. Hu Z, Li Y, Peng R, Liu J, Jia X, Liu X, et al. Multibranched stent-grafts for the treatment of thoracoabdominal aortic aneurysms: a systematic review and metaanalysis. J Endovasc Ther. 2016;23:626-33.

22. Greenberg RK, Lu Q, Roselli EE, Svensson LG, Moon MC, Hernandez AV, et al. Contemporary analysis of descending thoracic and thoracoabdominal aneurysm repair: a comparison of endovascular and open techniques. Circulation. 2008; 118:808-17.

23. Afifi RO, Sandhu HK, Trott AE, Nguyen TC, Miller CC, Estrera AL, et al. Redo thoracoabdominal aortic aneurysm repair: a single-center experience over 25 years. Ann Thorac Surg. 2017;103:1421-8.

Key Words: intercostal artery reattachement, thoracoabdominal aortic aneurysm repair, spinal cord ischemia, paraplegia, spinal cord protection 
TABLE E1. Operative characteristics comparing ICA management strategies by aneurysm extent

\begin{tabular}{|c|c|c|c|c|}
\hline Variable & ICA ligated & ICA reattached, island & ICA reattached, bypass & ICA reattached, loop \\
\hline \multicolumn{5}{|l|}{ TAAA I } \\
\hline Pump time (minutes/artery) & $-0.9(0.149)$ & $1.2(<.001)$ & $1.1(0.147)$ & $1.2(0.018)$ \\
\hline Clamp time (minutes/artery) & $-1.0(0.964)$ & $1.1(<.001)$ & $1.0(0.997)$ & $1.1(0.052)$ \\
\hline Cells saved (units/artery) & $1.0(0.484)$ & $1.0(0.908)$ & $1.1(0.501)$ & $1.5(0.053)$ \\
\hline Packed red blood cells (units/artery) & $-0.9(0.201)$ & $1.2(0.039)$ & $-0.7(0.055)$ & $-0.9(0.776)$ \\
\hline Fresh frozen plasma (units/artery) & $1.2(0.061)$ & $1.4(0.019)$ & $-0.9(0.864)$ & $1.9(0.029)$ \\
\hline Platelets (units/artery) & $1.1(0.269)$ & $1.3(0.084)$ & $-0.9(0.819)$ & $2.2(0.029)$ \\
\hline Intraoperative coagulopathy (OR/artery) & $1.1(0.596)$ & $0.8(0.314)$ & $1.4(0.137)$ & $2.0(0.010)$ \\
\hline Intraoperative complications (OR/artery) & $1.0(0.727)$ & $0.9(0.354)$ & $1.3(0.196)$ & $1.9(0.014)$ \\
\hline \multicolumn{5}{|l|}{ TAAA II } \\
\hline Pump time (minutes/artery) & $1.0(0.001)$ & $1.1(<.001)$ & $1.2(<.001)$ & $1.1(<.001)$ \\
\hline Clamp time (minutes/artery) & $1.0(0.001)$ & $1.1(<.001)$ & $1.1(0.009)$ & $1.1(<.001)$ \\
\hline Cells saved (units/artery) & $1.1(0.035)$ & $1.2(0.005)$ & $1.2(0.172)$ & $1.3(0.002)$ \\
\hline Packed red blood cells (units/artery) & $-0.9(0.215)$ & $1.1(0.189)$ & $-0.9(0.339)$ & $1.2(0.015)$ \\
\hline Fresh frozen plasma (units/artery) & $-0.9(0.459)$ & $-0.9(0.569)$ & $1.2(0.391)$ & $1.3(0.059)$ \\
\hline Platelets (units/artery) & $1.0(0.659)$ & $1.0(0.755)$ & $1.1(0.752)$ & $1.4(0.065)$ \\
\hline Intraoperative coagulopathy (OR/artery) & $1.1(0.097)$ & $0.8(0.120)$ & $1.4(0.125)$ & $1.9(0.011)$ \\
\hline Intraoperative complications (OR/artery) & $1.1(0.146)$ & $0.8(0.073)$ & $1.4(0.159)$ & $1.8(0.014)$ \\
\hline \multicolumn{5}{|l|}{ TAAA III } \\
\hline Pump time (minutes/artery) & $-1.0(0.704)$ & $1.2(<.001)$ & $1.1(0.053)$ & $1.0(0.732)$ \\
\hline Clamp time (minutes/artery) & $-1.0(0.926)$ & $1.1(<.001)$ & $1.0(0.480)$ & $-1.0(0.532)$ \\
\hline Cells saved (units/artery) & $1.1(0.483)$ & $1.3(0.033)$ & $-0.7(0.233)$ & $1.5(0.094)$ \\
\hline Packed red blood cells (units/artery) & $-0.9(0.399)$ & $1.1(0.194)$ & $-0.5(0.002)$ & $1.2(0.237)$ \\
\hline Fresh frozen plasma (units/artery) & $-0.9(0.685)$ & $1.1(0.644)$ & $-0.3(0.001)$ & $2.0(0.046)$ \\
\hline Platelets (units/artery) & $1.2(0.535)$ & $-0.8(0.422)$ & $-0.2(0.001)$ & $1.8(0.175)$ \\
\hline Intraoperative coagulopathy (OR/artery) & $1.6(0.045)$ & $1.1(0.674)$ & $0.4(0.285)$ & $2.0(0.039)$ \\
\hline Intraoperative complications (OR/artery) & $1.5(0.102)$ & $1.0(0.909)$ & $0.4(0.238)$ & $1.7(0.075)$ \\
\hline \multicolumn{5}{|l|}{ TAAA IV } \\
\hline Pump time (minutes/artery) & $1.0(0.475)$ & $1.1(0.014)$ & $1.3(0.004)$ & NA \\
\hline Clamp time (minutes/artery) & $-1.0(0.653)$ & $1.1(0.007)$ & $1.3(<.001)$ & NA \\
\hline Cells saved (units/artery) & $1.1(0.211)$ & $1.2(0.102)$ & $1.4(0.149)$ & NA \\
\hline Packed red blood cells (units/artery) & $1.2(0.185)$ & $1.5(0.060)$ & $1.5(0.025)$ & NA \\
\hline Fresh frozen plasma (units/artery) & $1.3(0.273)$ & $1.6(0.082)$ & $1.2(0.768)$ & NA \\
\hline Platelets (units/artery) & $1.6(0.174)$ & $1.9(0.067)$ & $1.4(0.564)$ & NA \\
\hline Intraoperative coagulopathy (OR/artery) & $3.7(0.025)$ & $1.9(0.019)$ & $1.5(0.310)$ & NA \\
\hline Intraoperative complications (OR/artery) & $3.5(0.030)$ & $1.8(0.025)$ & $1.4(0.359)$ & NA \\
\hline \multicolumn{5}{|l|}{ TAAA V } \\
\hline Pump time (minutes/artery) & $-1.0(0.647)$ & $1.2(0.003)$ & $1.2(0.085)$ & $1.2(0.269)$ \\
\hline Clamp time (minutes/artery) & $-0.9(0.079)$ & $1.1(0.001)$ & $1.1(0.353)$ & $1.1(0.214)$ \\
\hline Cells saved (units/artery) & $-1.0(0.809)$ & $-0.8(0.043)$ & $1.3(0.331)$ & $1.1(0.828)$ \\
\hline Packed red blood cells (units/artery) & $1.2(0.636)$ & $1.6(0.039)$ & $1.6(0.240)$ & $1.4(0.649)$ \\
\hline Fresh frozen plasma (units/artery) & $-0.7(0.298)$ & $1.7(0.084)$ & $2.8(0.046)$ & $1.3(0.759)$ \\
\hline Platelets (units/artery) & $-0.7(0.383)$ & $2.5(0.006)$ & $3.6(0.020)$ & $4.1(0.122)$ \\
\hline Intraoperative coagulopathy (OR/artery) & $1.9(0.189)$ & $1.2(0.647)$ & $2.6(0.033)$ & $0.0(0.987)$ \\
\hline Intraoperative complications (OR/artery) & $1.4(0.452)$ & $1.0(0.933)$ & $1.9(0.093)$ & $0.0(0.984)$ \\
\hline \multicolumn{5}{|l|}{ DTAA } \\
\hline Pump time (minutes/artery) & $-1.0(0.001)$ & $1.1(<.001)$ & $1.2(0.014)$ & $-0.9(0.071)$ \\
\hline Clamp time (minutes/artery) & $1.0(0.015)$ & $1.0(0.048)$ & $1.0(0.464)$ & $-1.0(0.289)$ \\
\hline Cells saved (units/artery) & $1.2(<.001)$ & $-1.0(0.327)$ & $-0.9(0.671)$ & $1.1(0.321)$ \\
\hline Packed red blood cells (units/artery) & $-0.9(0.111)$ & $1.2(0.007)$ & $1.2(0.708)$ & $1.0(0.859)$ \\
\hline Fresh frozen plasma (units/artery) & $-0.9(0.209)$ & $1.5(<.001)$ & $-0.8(0.636)$ & $-1.0(0.892)$ \\
\hline Platelets (units/artery) & $-0.9(0.385)$ & $1.2(0.137)$ & $-0.7(0.632)$ & $1.3(0.347)$ \\
\hline Intraoperative coagulopathy (OR/artery) & $0.9(0.353)$ & $0.8(0.129)$ & $1.7(0.172)$ & $1.3(0.319)$ \\
\hline Intraoperative complications (OR/artery) & $0.9(0.039)$ & $0.9(0.267)$ & $1.4(0.343)$ & $1.2(0.475)$ \\
\hline
\end{tabular}

$I C A$, Intercostal artery; TAAA, thoracoabdominal aortic aneurysm; OR, odds ratio; NA, not applicable; DTAA, descending thoracic aortic aneurysm. (C) 2018 Department of Cardiothoracic and Vascular Surgery, McGovern Medical School. 